\title{
Assessment of multiple hormone activities of a UV-filter (octocrylene) in zebrafish (Danio rerio)
}

\author{
Qiuya Y. Zhang a, b, Xiaoyan Y. Ma a, b, Xiaochang C. Wang a, b, *, Huu Hao ${ }^{\text {Ngo }}{ }^{\text {c }}$ \\ a International Science \& Technology Cooperation Center for Urban Alternative Water Resources Development, Key Lab of Northwest Water Resource, \\ Environment and Ecology, MOE, Engineering Technology Research Center for Wastewater Treatment and Reuse, Shaanxi Province, China \\ ${ }^{\mathrm{b}}$ Key Lab of Environmental Engineering, Shaanxi Province, Xi'an University of Architecture and Technology, No. 13, Yanta Road, Xi'an 710055, China \\ c Centre for Technology in Water and Wastewater, School of Civil and Environmental Engineering, University of Technology Sydney, Sydney, NSW 2007, \\ Australia
}

\section{H I G H L I G H T S}

- Octocrylene (OCT) can accumulate in fishes up to sufficiently high levels to cause adverse effects on the endocrine system.

- The accelerated ovary development indicates that OCT has the effect on sex-endocrinology.

- The gene alterations address that OCT has the multiple hormone activities.

\section{A R T I C L E I N F O}

\section{Article history:}

Received 14 March 2016

Received in revised form 8 June 2016

Accepted 9 June 2016

Available online 20 June 2016

Handling Editor: David Volz

Keywords:

UV filters

Octocrylene (OCT)

Zebrafish

Hormone activity

\begin{abstract}
A B S T R A C T
In this study, zebrafish (Danio rerio) were exposed to a UV-filter-octocrylene (OCT) with elevated concentrations for $28 \mathrm{~d}$. The total body accumulation of OCT in zebrafish was found to reach 2321.01 ("L" level), 31,234.80 ("M" level), and 70,593.38 $\mathrm{ng} \mathrm{g}^{-1}$ ("H" level) when the average OCT exposure concentration was controlled at 28.61, 505.62, and $1248.70 \mu \mathrm{g} \mathrm{L} \mathrm{L}^{-1}$, respectively. Gross and histological observations as well as RT-qPCR analysis were conducted to determine the effects of OCT accumulation on zebrafish. After exposure, the gonad-somatic index and percentage of vitellogenic oocytes were found to increase significantly in the ovaries of female zebrafish at the $\mathrm{H}$ accumulation level. Significant upregulation of esr1 and cyp19b were observed in the gonads, as well as vtg1 in the livers for both female and male zebrafish. At $\mathrm{M}$ and $\mathrm{H}$ accumulation levels, apparent down-regulation of ar was observed in the ovaries and testis of the female and male zebrafish, respectively. Although the extent of the effects on zebrafish differed at different accumulation levels, the induction of $v \operatorname{tg} 1$ and histological changes in the ovaries are indications of estrogenic activity and the inhibition of esr1 and ar showed antiestrogenic and antiandrogenic activity, respectively. Thus, as OCT could easily accumulate in aquatic life such as zebrafish, one of its most of concern hazards would be the disturbance of the histological development and its multiple hormonal activities.
\end{abstract}

(c) 2016 Elsevier Ltd. All rights reserved.

\section{Introduction}

By virtue of the increased public awareness of the hazards associated with overexposure to ultraviolet (UV) radiation, UV filters are now commonly added to products such as creams, lipsticks,

\footnotetext{
* Corresponding author. International Science \& Technology Cooperation Center for Urban Alternative Water Resources Development, Key Lab of Northwest Water Resource, Environment and Ecology, MOE, Engineering Technology Research Center for Wastewater Treatment and Reuse, Shaanxi Province, China.

E-mail address: xcwang@xauat.edu.cn (X.C. Wang).
}

and in the UV-protection of numerous materials and products (Balmer et al., 2005; Fent et al., 2010). It is estimated that about 10,000 tons of UV filters are produced annually for the global market (Danovaro et al., 2008). There are two main categories of UV filters: 1) Inorganic filters composed of titanium dioxide and/or zinc oxide for scattering and reflecting UV light, and 2) organic compounds such as 2-ethyl-hexyl-4-trimethoxycinnamate (EHMC) or benzophenone-3 (BP-3), which work by absorbing UV-light. In the European Union, 28 UV filters have been registered in total (Schlumpf et al., 2008). All have been identified as potentially dangerous pollutants to the aquatic environment. 
UV filters can easily enter the aquatic system via direct or indirect pathway such as being washed off the skin during bathing and swimming. Because the molecules of most UV filters are very stable, it is difficult for them to be completely removed by conventional wastewater treatment processes. The treated effluents may thus be the primary source of UV filters entering the aquatic environment (Buser et al., 2006; Fent et al., 2010). High concentrations of EHMC (up to 20,070 $\mathrm{ng} \mathrm{L}^{-1}$ ) and 4-methylbenzylidene camphor (up to $960 \mathrm{ng} \mathrm{L}^{-1}$ ) have been measured from domestic wastewaters (Kupper et al., 2006), and, if they are not sufficiently removed by treatment, may significantly contaminate the receiving water bodies due to effluent discharge. In surface waters, benzophenone-4 (BP-4) has been measured at levels as high as $849 \mathrm{ng} \mathrm{L} \mathrm{L}^{-1}$ (Rodil et al., 2008). EHMC was measured at 26-5610 $\mathrm{ng} \mathrm{L}^{-1}$ in the source water for drinking water supply (Loraine and Pettigrove, 2006).

Of the most commonly used UV filters, octocrylene (OCT) has attracted significant research attention in the environmental protection field because it is more refractory and hydrophobic than other UV filters (Rodil et al., 2009). OCT has been found in several different water bodies across the globe. Seawater collected from Hong Kong, for example, can be contaminated with OCT at up to 103-6812 $\mathrm{ng} \mathrm{L}^{-1}$ (Tsui et al., 2015). It has also been reported that the concentration of OCT in lake water ranges from 2 to $27 \mathrm{ng} \mathrm{L}^{-1}$ (Poiger et al., 2004). OCT has even been detected in tap water at levels as high as $170 \mathrm{ng} \mathrm{L}^{-1}$ (Díaz-Cruz et al., 2012). Authors have also monitored the presence of OCT in the effluent of domestic wastewater treatment plant to find that its concentration can reach 0.56-1.8 $\mu \mathrm{g} \mathrm{L}^{-1}$ (unpublished data).

The Kow of OCT is as high as about $10^{7}$, which allows it to easily accumulate in aquatic life. In a Swiss lake, OCT was detected from the mussel of brown trout as $2400 \mathrm{ng} \mathrm{g}^{-1}$ lipid weight (l.w.) (Buser et al., 2006). In a remote Brazilian coastal area, the accumulated OCT in Franciscana dolphins was as high as $89-782$ ng g $^{-1}$ (l.w.) (Gago-Ferrero et al., 2013). OCT accumulations of 25-11,875 $\mathrm{ng} \mathrm{g}^{-1}$ body weight (b.w.) were also reported in the liver of cod in Oslofjord (Langford et al., 2015). Unfortunately, relatively little information is available regarding the toxic effect of OCT accumulation in aquatic organisms.

There has been growing concern regarding the endocrinedisrupting effect of UV filters on aquatic life, for example, the alterations in gonad histology of mature fathead minnows caused by benzophenone-2 (BP-2) (Weisbrod et al., 2007). Many UV filters have been found to be hormonally active and show agonistic and/or antagonistic effects towards nuclear receptors, estrogen responsive genes, and steroidogenesis (Zucchi et al., 2010; Christen et al., 2011; Kim et al., 2014). Accordingly, any study on the potential risk associated with OCT may also need to be concentrated on its possible endocrine disrupting effect when it is accumulated in the bodies of aquatic animals. Zebrafish (Danio rerio) makes an excellent vertebrate model for assessing the toxicity of this manner of chemicals in vivo, especially when analyzing the action mode (Reimers et al., 2004). Previous studies have also shown that in order to evaluate the ultimate toxicological effect of a target chemical on aquatic life, experimental conditions should be established appropriately for the chemical to be accumulated in the test aquatic animal to appreciably high levels during a certain duration of exposure (Zucchi et al., 2010; Blüthgen et al., 2012). In the case of zebrafish, OECD guidelines specify that $28 \mathrm{~d}$ is a reasonable exposure time $(\mathrm{OECD}, 1996)$ to control target chemical in the experimental solution to sufficiently elevated concentration.

The objective of this study was to gain knowledge on the endocrine disrupting potential of OCT on aquatic life by using zebrafish for in vivo bioassay. We conducted gross and histological observations as well as RT-qPCR analysis to monitor the multiple hormone activities of OCT after the chemical was accumulated to a certain level.

\section{Materials and methods}

\subsection{Chemicals}

2-Ethylhexyl-2-cyano-3,3-diphenylpropenoate (OCT, CAS No:6197-30-4, purity $\geq 95 \%$ ) was purchased from TCI (Tokyo, Japan). Dimethylsulfoxide (DMSO), methanol, and dichloromethane of HPLC grade were purchased from Fisher Scientific (Shanghai, China). Stock solutions of OCT $\left(1,10,30 \mathrm{~g} \mathrm{~L}^{-1}\right)$ were prepared by dissolution in DMSO and stored in a dark environment at $4{ }^{\circ} \mathrm{C}$ between uses. Before exposure, the stock solutions were diluted and DMSO solvent concentration maintained at $\leq 0.01 \%$ (v/ v).

\subsection{Maintenance of zebrafish}

Juvenile zebrafish (about five months old, mean body length $3.22 \mathrm{~cm}$, mean body weight $0.28 \mathrm{~g}$ ) was obtained from an animal lab (Hebei, Shijiazhuang) and transferred to an ultra-white fish tank. Before conducting the experiment, female and male zebrafish was separately acclimatized for one month in reconstituted tap water with a total hardness of $125 \mathrm{mg} \mathrm{L}^{-1}$ as $\mathrm{CaCO}_{3}$ and an electrical conductivity of $270 \mu \mathrm{S} \mathrm{cm} \mathrm{cm}^{-1}$. The water temperature was kept constant at $27 \pm 1{ }^{\circ} \mathrm{C}$ with a photoperiod set to $14: 10 \mathrm{~h}$ light/dark. Zebrafish was fed twice daily with a combination of brine shrimp and flake fish food. Water parameters (nitrate, nitrite, $\mathrm{pH}$ ) were measured daily and oxygen saturation was maintained at $\geq 80 \%$.

\subsection{Exposure of zebrafish to $O C T$}

Adult zebrafish was exposed to OCT solutions including a blank control, solvent control (DMSO, $\leq 0.01 \%$ ), and a series of prepared OCT solution $\left(100,1,000,3000 \mu \mathrm{g} \mathrm{L}^{-1}\right)$ for $28 \mathrm{~d}$. The concentrations and duration of exposure were determined based on previous studies on other UV filters (Christen et al., 2011) and OECD guidelines (OECD, 1996). A static-renewal procedure was conducted during exposure. Zebrafish of similar size was removed from the culture tank randomly and placed into $5 \mathrm{~L}$ glass beakers covered with gauze. Every 48 h, zebrafish was transferred to new exposure solutions and the surplus food and faeces were immediately removed by siphoning. Throughout the entire exposure period, zebrafish was fed as previously described. Their mortality, development, and abnormal behaviors were recorded daily.

\subsection{Analysis of OCT in exposure water and zebrafish}

To determine the actual OCT concentrations during exposure, aliquots of $200 \mathrm{~mL}$ exposure water from each treatment group were taken at the beginning $(0 \mathrm{~h})$, after $24 \mathrm{~h}$, and prior to water renewal (48 h). The adsorption and accumulation of OCT in the zebrafish may not have been consistent during the whole exposure, resulting in variations in OCT level in the water; thus, in order to accurately obtain actual OCT concentrations, samples were taken on days $1-3,10-12$, and $19-21$, respectively.

About $200 \mathrm{~mL}$ aliquots of each nominal concentration were taken for analysis at $0 \mathrm{~h}, 24 \mathrm{~h}$, and $48 \mathrm{~h}$. The water samples were stored at $-20^{\circ} \mathrm{C}$ in brown glass bottles until analysis. Watersample extraction and chemical analysis were performed as follows. Before solid-phase-extraction, the $\mathrm{pH}$ of exposure samples was adjusted to 3 with hydrochloric acid. Agilent C18 (500 mg and 3 cc) cartridges were conditioned with $10 \mathrm{~mL}$ dichloromethane, $10 \mathrm{~mL}$ methanol, and $10 \mathrm{~mL}$ Milli-Q water, then water samples were passed through 
at a rate of $5 \mathrm{~mL} / \mathrm{min}$. The cartridges were washed with $10 \mathrm{~mL}$ Milli$\mathrm{Q}$ water and air dried for about $30 \mathrm{~min}$, then the retained analyte was eluted with $10 \mathrm{~mL}$ dichloromethane. The extraction was evaporated to dryness under a gentle stream of $\mathrm{N}_{2}$ at $30{ }^{\circ} \mathrm{C}$, reconstituted in $1 \mathrm{~mL}$ methanol, and stored in the dark at $4{ }^{\circ} \mathrm{C}$ until analysis. Chemical analysis of OCT concentration was carried out by high performance liquid chromatography (HPLC) coupled to UVdetection at $290 \mathrm{~nm}$. The chromatographic mobile phase composed of $85 \%(\mathrm{v} / \mathrm{v})$ methanol in Milli-Q water was subjected to a flow rate of $0.9 \mathrm{~mL} / \mathrm{min}$. The chromatographic separation was performed with a Hypersil BDS-C18 column $(4.6 \mathrm{~mm} \times 250 \mathrm{~mm}$, $5 \mu \mathrm{m}$ particle size) at a temperature of $30^{\circ} \mathrm{C}$. Extract samples $20 \mu \mathrm{L}$ in volume were injected in duplicate and finished in $12 \mathrm{~min}$ with an auto-sampler.

Zebrafish was extracted according to previously published methods (Weisbrod et al., 2007) with some modifications. Individual whole zebrafish was homogenized in a tissue grinder (Sangon, EQ 6002) together with 3 mL HPLC water (the same quantity as fish weight). Liquid-liquid extraction was then performed with a mixture of ethyl acetate, $n$-heptane, and HPLC water $(1: 1: 1, \mathrm{v} / \mathrm{v} / \mathrm{v})$. The volume of each eluent added was proportional to the initial amount of HPLC water. The mixture was rigorously shaken for $10 \mathrm{~min}$; then the supernatant was collected after centrifugation at $5000 \mathrm{~g}$ for $10 \mathrm{~min}$ at $4{ }^{\circ} \mathrm{C}$. The extraction was repeated twice. The supernatants were combined and filtered through $0.45 \mu \mathrm{m}$ Acrodisc $^{\mathbb{B}}$ syringe filter, then the extraction was dried with a gentle stream of nitrogen at $30^{\circ} \mathrm{C}$ and the analytes were reconstituted in $200 \mu \mathrm{L}$ methanol. Finally, the residues were centrifuged for $10 \mathrm{~min}$ at room temperature and the final supernatant was subjected to HPLC analysis. The detection of OCT in exposed zebrafish was similar to that of water samples. At the end of the exposure period, the gonads, livers, and brains were excised, snap-frozen in liquid nitrogen, and stored at $-80^{\circ} \mathrm{C}$ until qRT-PCR analysis.

\subsection{Gross and histological observations}

To assess the effect of OCT on the development of zebrafish after exposure, the condition factor $(C F=$ (weight (g)/length $(\mathrm{cm}) \times 100)$ ) was measured as well as the gonad-somatic index (GSI = gonad weight ( $\mathrm{g}$ )/body weight $(\mathrm{g})$ ) according to methods used by previous researchers (Weisbrod et al., 2007; Christen et al., 2011). At the end of exposure, the ovaries of five female zebrafish was excised and encased in O.C.T. (Sakura, USA). Sections $(10 \mu \mathrm{m})$ were cut with a CM1850 Freezing Microtome (Leica Biosystems, Germany) and stained with haematoxylin and eosin (H\&E) and pictures of three randomly selected fields of vision were taken with an optical microscope (Nikon 90i) to observe the histology of the ovaries of the female zebrafish. Three fields from each region of the ovary were randomly selected to observe the distribution of primary oocytes, previtellogenic oocytes, and vitellogenic oocytes in the ovaries. The frequencies of the above cells were determined according to Pereira et al. (2013).

\section{6. $R T-q P C R$ analysis}

Total RNA was extracted from the brains, livers, and gonads $(n=5)$ and pooled using a Takara MiniBest Universal RNA Extraction kit (Takara, Japan) according to the manufacturer's instructions. To guarantee the concentration and quality of RNA, RNA was analyzed with a NanoDrop 1000 spectrophotometer and electrophoresis. Only RNA samples of purity between 1.8 and 2.0 for both ratios of $260 / 280 \mathrm{~nm}$ and $260 / 230 \mathrm{~nm}$ and RNA intensity ratio for $28 \mathrm{~S} / 18 \mathrm{~S}$ of about $2: 1$ were used for RT-qPCR.

Total RNA templates were reversely transcribed to cDNA and stored at $-20{ }^{\circ} \mathrm{C}$ for subsequent RT-qPCR analysis. The three-step real-time PCR profile was completed according to previously published methods (Christen et al., 2011). In this study, certain target genes involved in hormonal activity (Table 1) were selected for analysis: estrogen responsive gene ( $v \operatorname{tg} 1)$, nuclear receptor (esr1, ar), and steroid metabolism (cyp19b, rbp2a). The18S ribosomal RNA (18S $r R N A$ ) was selected as a reference gene for normalization, because its expression profile did not vary either in different conditions or different tissues. The relative linear quantity of target molecules relative to the calibrator was calculated by $2^{-\triangle \triangle \mathrm{ct}}$ (Livak and Schmittgen, 2001). Transcriptional alterations of different genes are expressed as fold change $(\log 2)$.

\subsection{Data analysis and statistics}

Data were illustrated graphically as shown below with GraphPad ${ }^{\circledR}$ Prism5 (GraphPad Software, San Diego, CA, USA). Significant differences in transcript levels were analyzed by one-way analysis of variance (ANOVA). Differences between treatments were analyzed by Newman-Keuls test to compare treatment means with controls. Results are given as mean \pm standard deviation (SD). Differences were considered statistically significant at $p \leq 0.05$.

\section{Results and discussion}

\subsection{Chemical analysis}

Samples were analyzed by HPLC at $0 \mathrm{~h}, 24 \mathrm{~h}$, and $48 \mathrm{~h}$ to determine the actual concentration of OCT in the prepared solution (Fig. 1). All actual concentrations were lower than the

Table 1

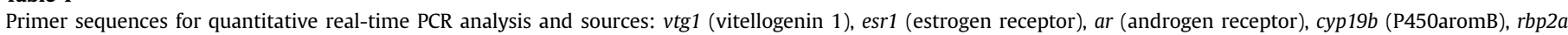
(retinol-binding protein type II), 18S rRNA (18S ribosomal RNA).

\begin{tabular}{|c|c|c|c|c|}
\hline Target gene & GenBank number & Sense primer $\left(5^{\prime}-3^{\prime}\right)$ & Antisense primer $\left(5^{\prime}-3^{\prime}\right)$ & Product size (bp) \\
\hline $\operatorname{vtg} 1^{a}$ & AY034146 & AGCTGCTGAGAGGCTTGTTA & GTCCAGGATTTCCCTCAGT & 94 \\
\hline$e s r 1^{b}$ & NM_152959 & TGAGCAACAAAGGAATGGAG & GTGGGTGTAGATGGAGGGTTT & 163 \\
\hline$a r^{c}$ & NM_001083123 & CACTACGGAGCCCTCACTTGCGGA & GCCCTGAACTGCTCCGACCTC & 237 \\
\hline cyp $19 b^{d}$ & AF183908 & CGACAGGCCATCAATAACA & CGTCCACAGACAGCTCATC & 94 \\
\hline$r b p 2 a^{e}$ & AF363957 & GGAGATGCTCAGCAATGACA & TCTGCACAATGACCTTCGTC & 110 \\
\hline $18 s r R N A^{f}$ & Y855349.1 & AAACGGCTACCACATCCAAG & TTACAGGGCCTCGAAAGAGA & 116 \\
\hline
\end{tabular}

\footnotetext{
Date sources:

a (Hoffmann et al., 2006).

b (Martyniuk et al., 2007).

c (Hossain et al., 2008).

d (Arukwe et al., 2008)

e (Zucchi et al., 2011).

f (Wintz et al., 2006).
} 


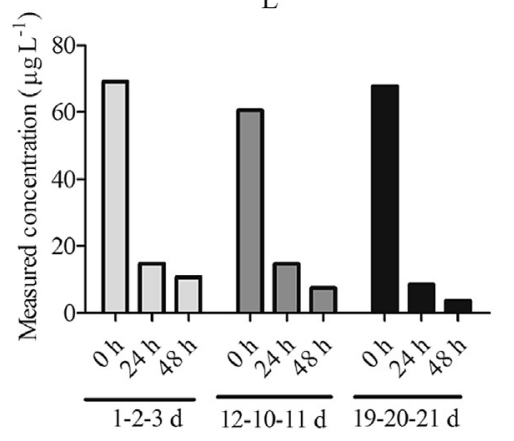

M

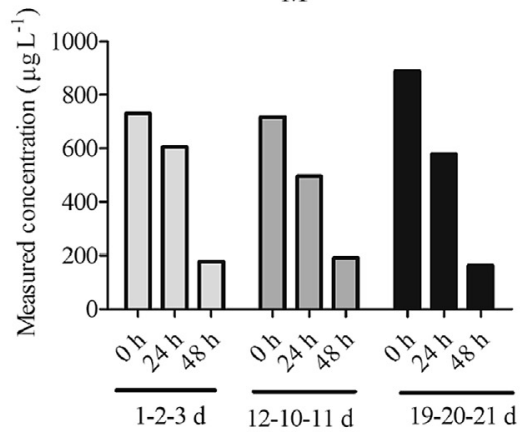

$\mathrm{H}$

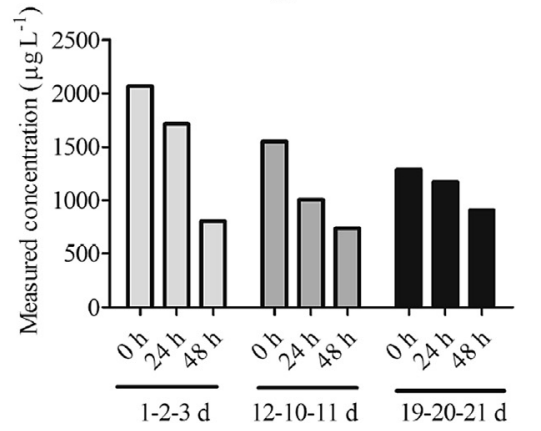

Fig. 1. Measured concentrations of OCT at prepared concentrations of $100,1,000$, and $3000 \mu \mathrm{g} \mathrm{L}^{-1}$.

corresponding prepared levels. The actual concentration of OCT markedly decreased with the extension of exposure time during each water renewal. The mean actual exposure concentration within $48 \mathrm{~h}$ was $28.61,505.62$, and $1248.70 \mu \mathrm{g} \mathrm{L}^{-1}$ at the prepared level of $100,1,000$, and $3000 \mu \mathrm{g} \mathrm{L}{ }^{-1}$, respectively. Based on the results of our preliminary experiment on the physicochemical properties of OCT, there was no significant change in OCT solubility in water over $72 \mathrm{~h}$ (unpublished data), which ruled out the degradation of OCT during exposure. Additionally, the data obtained from the exposure solution without zebrafish showed no further significant decrease in OCT. To this effect, we hypothesized that the decrease in OCT in the exposure water was caused by several factors including uptake into zebrafish or adsorption to surplus food or faeces rather than degradation.

OCT was also detected in all exposed zebrafish except the control. To be precise, the total body burden (TBB) of OCT as shown in Fig. 2 reached up to $2321.01(\mathrm{~L}), 31,234.70(\mathrm{M})$, and 70,593.38 $\mathrm{ng} \mathrm{g}^{-1}$ (b.w.) (H). By comparing the TBB of OCT in zebrafish in the present study to that observed in previous studies, we confirmed that the residual concentrations of OCT in zebrafish were within the scope of the concentrations in the fishes living in surface water over long periods of time. For example, the OCT content can reach up to $2400 \mathrm{ng} \mathrm{g}^{-1}$ (l.w.) in brown trout (Buser et al., 2006) and $1,1875 \mathrm{ng} \mathrm{g}^{-1}$ (b.w) in cod (liver) (Langford et al., 2015).

The bioaccumulation factors (BCF) of OCT in zebrafish at the accumulation levels of "L", "M", and "H" were 81, 62 and 56, respectively (Fig. 2) - a similar but lower range compared to the TBB. In general, without any adverse effect of the OCT exposure, the

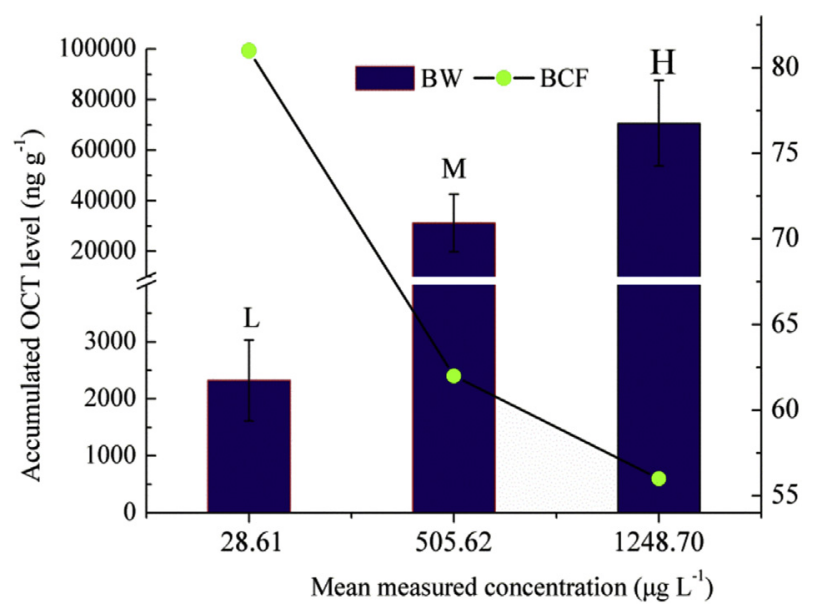

Fig. 2. Accumulated OCT levels and BCF of OCT in zebrafish exposed to actual OCT levels of 28.61, 505.62, and $1248.70 \mu \mathrm{g} \mathrm{L}^{-1}$. enrichment of OCT in zebrafish can be expected to equilibrate eventually, and the BCF to become constant. In this study, OCT displayed a similar bioaccumulation profile with another quickly metabolized UV filter, BP-3 (19-94) (Blüthgen et al., 2012). Gomez et al. (2012) pointed out that the uptake of OCT is rapid, but is followed by elimination within $24 \mathrm{~h}$. OCT is also known to be excreted to some extent (Gago-Ferrero et al., 2015). Thus, the metabolism and/or excretion of OCT in vivo can explain the low BCF despite the high lipophilicity of OCT.

\subsection{Gross observation}

During exposure, no abnormal behavior or mortality were observed among the exposed zebrafish. Furthermore, no significant differences in $C F$ occurred in the OCT-exposed zebrafish compared to the control (Fig. 3A and B). The GSI of males did not change significantly (Fig. 3C). However, the $\mathrm{H}$ accumulation level showed a significant increase in GSI in the ovaries of females (Fig. 3D).

GSI is a highly comprehensive physiological index that reflects the level of sex hormones and reveals the impact of exogenous estrogen to fishes (Ankley et al., 2001). Diuron metabolites lead to significant estrogenic activity associated with ovary development with the increase of GSI in O. Niloticus females (Boscolo Pereira et al., 2016), for example. The results of the present study indicate that OCT has estrogenic activity effects once accumulated in female zebrafish to a certain degree.

\subsection{Ovary histology}

Based on the GSI changes in females, we further investigated the histological development of ovaries in the exposure solution. Ovarian sections of zebrafish in the blank (water) showed a normal frequency distribution at ovarian lamellae, including primary oocytes (PV, with a large nucleus, centrally positioned with numerous nucleoli) previtellogenic oocytes $(\mathrm{V}$, with a large number of cortical alveoli vesicles) and vitellogenic oocytes (Oo, where cortical alveoli vesicles were no longer observed, oocytes were at their maximum size and were filled with protein yolk granules) (Fig. 4A). The ovaries of female zebrafish with $\mathrm{H}$ level OCT accumulation mainly revealed heavy vitellogenic oocytes characterized by deposition in the cytoplasm exogenous yolk (Fig. 4C and D). Moreover, quantitative analysis of the oogenesis (Fig. 5) showed a decrease in the percentage of primary oocytes $(13 \%, p \leq 0.001)$, but a significant increase in vitellogenic oocytes $(20 \%, p \leq 0.001)$ of ovaries with the $\mathrm{H}$ accumulation level.

Although gonad development is highly complex, external conditions can provide very useful information; sex reversal, for example, may occur if the gonad is exposed to endocrine disruptors 

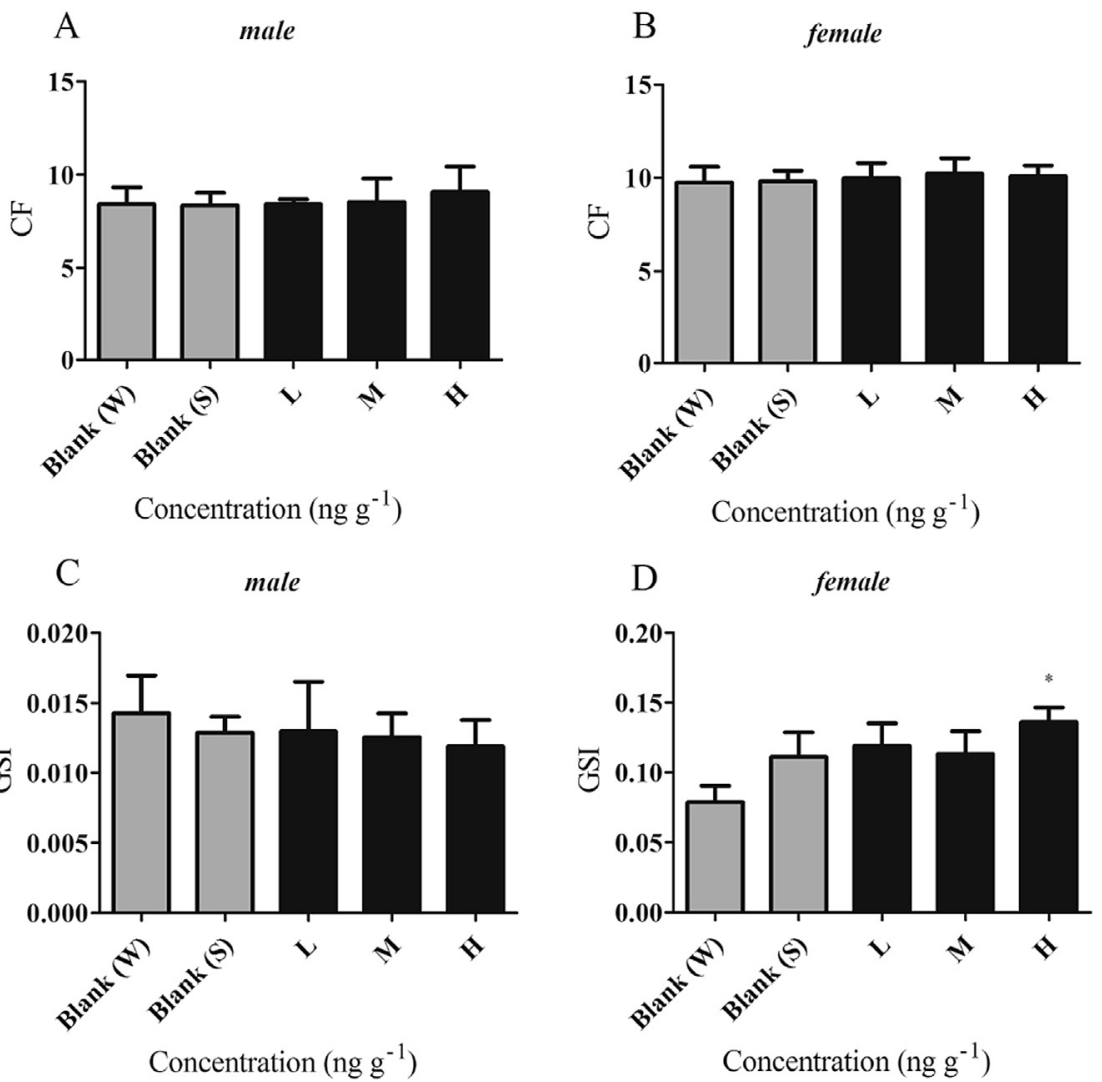

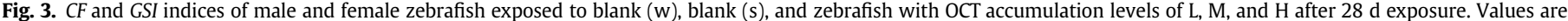
mean \pm SD. Asterisks $\left({ }^{*}\right)$ indicate statistical significance $\left({ }^{*} p \leq 0.05\right)$.

during critical development periods (Scholz and Gutzeit, 2000; McAllister and Kime, 2003). Nagahama and Yamashita (2008) demonstrated that E2 regulates ovarian development through the control of vitellogenin synthesis in the liver during the oocyte growth period. Vitellogenic oocytes are also known to significantly increase in size due to the presence of vitellogenin (Lubzens et al.,
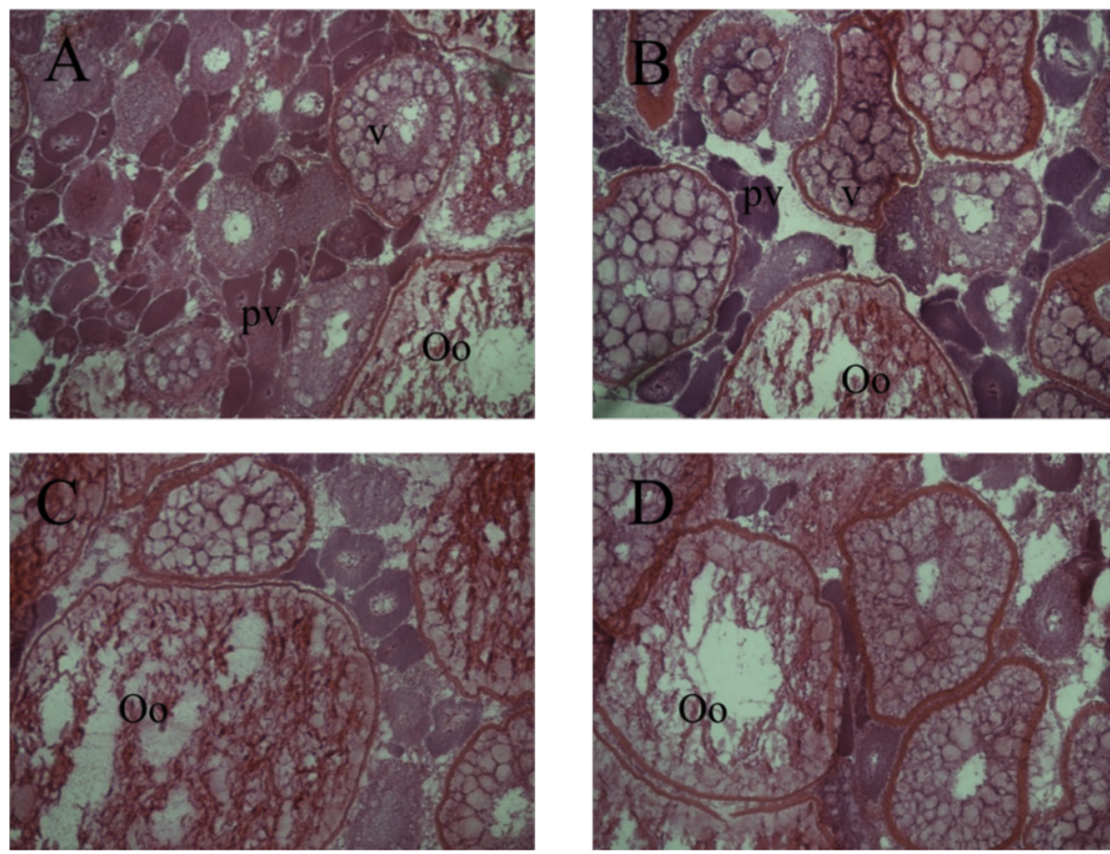

Fig. 4. Histological section of ovaries of female zebrafish exposed in blank (water) (A), and zebrafish with OCT accumulation level of L (B), M (C), and H (D). PV: primary oocytes; V: previtellogenic oocytes; Oo: vitellogenic oocytes. 


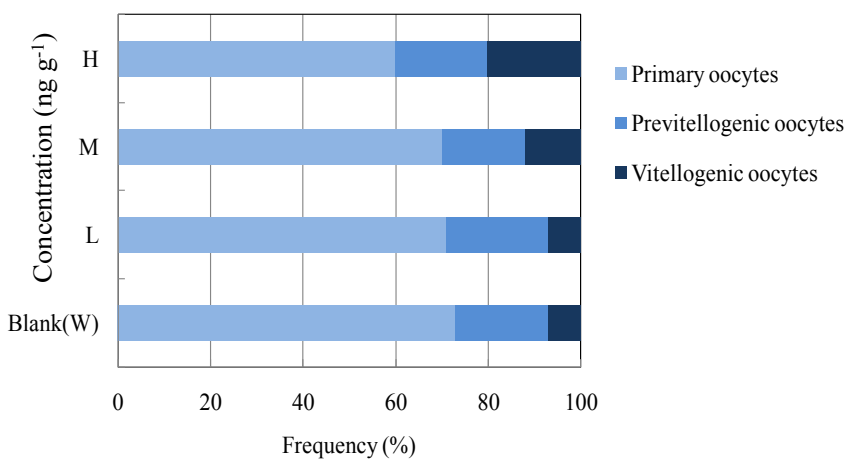

Fig. 5. Relative percentage of different stages of oogenesis in ovaries of female zebrafish exposed to blank (water) (A), and zebrafish with L, M, and H OCT accumulation level. Asterisks $\left({ }^{*}\right)$ indicate statistical significance $\left({ }^{*} p \leq 0.05\right)$.

2010). In this study, the increased GSI and percentage of final vitellogenic oocytes in the females with $\mathrm{H}$ level accumulation of OCT was likely directly caused by the induction of vitellogenin. This hypothesis was further validated by our subsequent analysis of $v \operatorname{tg} 1$ mRNA expression in the liver. The effect of OCT on the development of ovaries was identical to that of EHMC, whereby a significant increase in vitellogenic oocytes was observed at $394 \mu \mathrm{g} \mathrm{L}^{-1}$ (Christen et al., 2011). Similarly, the UV filter BP-2 has been shown to cause increased follicular atresia and even adverse effects on reproduction (Weisbrod et al., 2007). Taken together, these results indicate that high accumulation of OCT can interfere with the endocrine system by accelerating the ovaries and development of zebrafish.

\subsection{Effects of OCT on hormonal activity and steroidogenesis}

Our histological observations indicated that high accumulation of OCT may have a significant effect on the endocrine system. In effort to better understand the effects of OCT accumulation on aquatic life, the differential expression of the target genes in different tissues was analyzed. The transcriptions of several genes involved in hormonal pathways were observed in the brains, gonads, and livers (Fig. 6).

The expression pattern of esr1 in the gonad showed an overall up-regulated tendency. The modulation of this sex-steroid receptor was in line with previous studies on UV filters, where an induction of estrogen receptors (ERs) has been consistently observed (specifically for EHMC) (Inui et al., 2003). There is ample empirical evidence for the fact that the biological impact of exogenous estrogens extend beyond the gonads to other bodily systems, including the brain (Engler-Chiurazzi et al., 2016). An overall downregulation of esr1 was observed in the brain in our zebrafish samples.

Interference with ERs is a well-identified key event in the initiation of adverse outcomes (Sonavane et al., 2016). The downregulation of esr1 that we observed is related to the antiestrogenic activity of OCT in the brain, in accordance with results obtained in vitro in a previously published recombinant yeast assay (Kunz and Fent, 2006). As a ligand dependant transcription factor, $E R$ transduces hormone signals into a large variety of physiological responses in various organs such as reproductive organs (Ascenzi et al., 2006). Thus, different modulations of OCT on the expression of esr1 in different organs highlight the importance of analyzing transcription profiles in multiple tissues.

Exogenous estrogen can interfere with the endocrine system via multiple mechanisms of action. A significant inhibition of the expression of ar was observed in the gonads of males with $\mathrm{M}$ and $\mathrm{H}$ OCT accumulation levels and in female zebrafish with the $\mathrm{H}$ accumulation level, again in accordance with previous in vitro data showing that OCT is submaximal to full antiandrogenic activity in recombinant yeast carrying $h A R$ (Kunz and Fent, 2006). By comparison, the estrogenic EE2 produced a down-regulation of the ar transcript (Filby et al., 2007). In short, antiandrogenic activity of OCT cannot be ruled out in vivo. Christen et al. (2011) pointed out that potential changes in transcriptions of hormone receptors may be partially responsible for the histological changes in the testes and ovaries of exposed fishes. Thus, we would assert that the regulation of esr 1 and ar in the ovaries partially promotes ovarian development.

The accumualtion of OCT slightly affected the expression of genes involved in steroidogenesis. There was a significant upregulation of cyp19b (cytochrome p450 aromatase) in the brain of males with M and H OCT accumualtion levels. Cyp19 is considered a sensitive, convenient signal of organic xenobiotics in the aquatic environment (Hinfray et al., 2006), and estrogens are known to enhance the transcription of cyp19b in the brains of adult zebrafish (Mouriec et al., 2009; Callard et al., 2001). Certainly, up-regulation of cyp $19 b$ in the brain of male zebrafish can be interpreted as an estrogenic response. In addition, cyp19b is an important hormone involved in controlling the reproductive process in teleosts (Kazeto et al., 2001; Kuhl et al., 2005). The ovaries of female zebrafish with the $\mathrm{M}$ and $\mathrm{H}$ OCT accumulation levels showed a significant increase in cyp $19 b$, but the gene expression only increased in the testis of male zebrafish at the $\mathrm{H}$ accumulation level (Fig. 6E and F). The OCT accumulation-mediated induction of cyp $19 \mathrm{~b}$ mRNA is likely to promote ovarian maturation, because this enzyme catalyzes the final, rate-limitingstep in the conversion of testosterone into estradiol in the gonads (Simpson et al., 1994). We found that exposure to OCT inevitably altered the transcription of steroidogenesis (cyp19b). Further research is needed to confirm whether OCT affects plasma sex steroid levels and/or fertility and reproduction in adult fish.

Exposure of zebrafish to OCT resulted in a significant upregulation of $v \operatorname{tg} 1$ in the liver at the $\mathrm{H}$ OCT accumulation level. $V t g$ mRNA is always induced in zebrafish by exposure to (xeno) estrogen, so the induction of vitellogenin in the liver is a sensitive and reliable indicator of exposure to exogenous estrogen (Sumpter and Jobling, 1995; Liu et al., 2010). In contrast to our findings, Blüthgen et al. (2014) observed no significant alteration of vtg1 in the liver after $8 \mathrm{~d}$ exposure. The exposure time, concentrations, and development stage may impact the regulation of gene transcription. Especially considering the immediate decrease in OCT after water-renewal, it seems likely that transient OCT exposure affects the transcriptional level. The fact that $30 \mathrm{~d}$ exposure of fish to EE2 results in an up-regulation of $v \operatorname{tg}$ (Bogers et al., 2006) implies that OCT has estrogenic activity in the liver. As discussed above, endogenous E2 modulates ovarian development by regulating vitellogenin synthesis. Therefore, it is possible that changes in $v \operatorname{tg} 1$ expression in the liver accelerated ovarian development.

$R b p 2 a$ retinoids play a significant role in various physiological processes such as cell growth, differentiation, and reproduction (Chen et al., 2012). In this study, the induction of rbp2a was observed in the livers of males and females even at the L OCT accumulation level (Fig. 6G and H). Many studies have reported alterations of retinoids in various species due to environmental contaminants - McKearin et al. (1986), for example, unequivocally demonstrated that vertebrate $r b p$ mRNA levels are regulated by steroidogenesis. Levy et al. (2004) reported that rbp is up-regulated by $E 2$ and EE2 in cultured $X$. laevis hepatocytes, which provides evidence that retinoids are a biomarker for detecting the specific actions of pure EDC. The changes in $r b p 2 a$ that we observed therefore suggested an environmental endocrine-disruption effect of OCT on zebrafish. Moreover, when there is inhibited absorption 
A

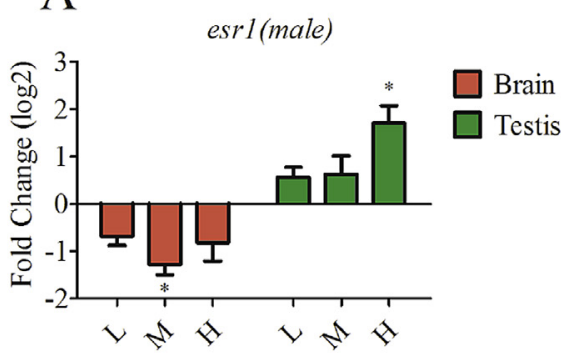

$\mathrm{C}$ ar(male)

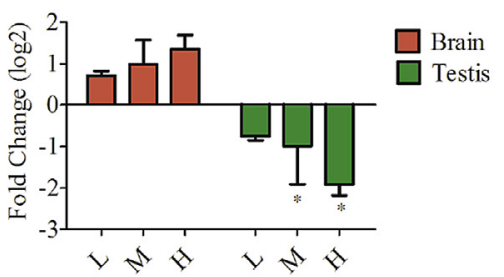

$\mathrm{E}$ cyp19b(male)
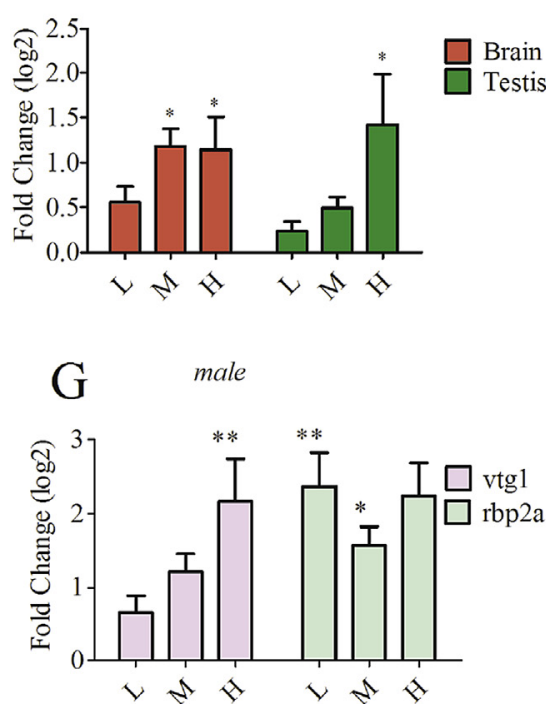

B

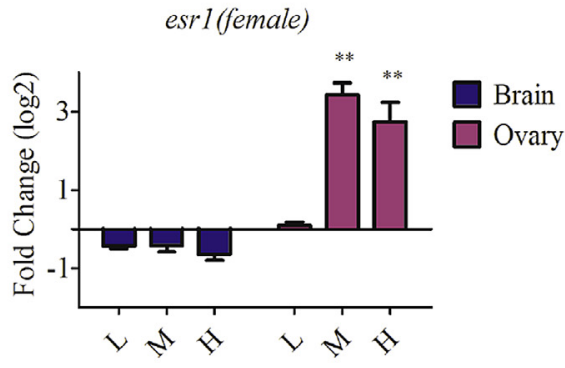

$\mathrm{D}$

ar(female)

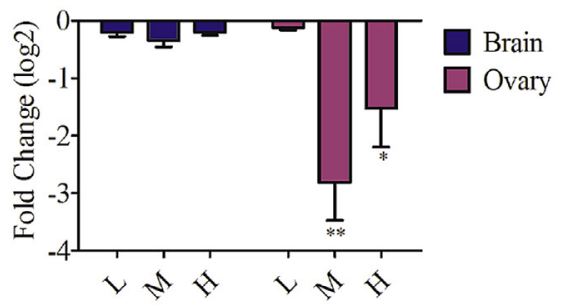

$\mathrm{F}$

cyp19b(female)
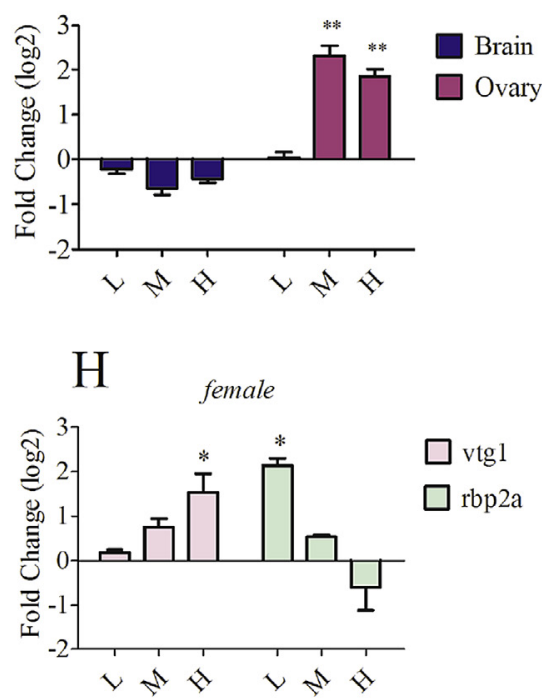

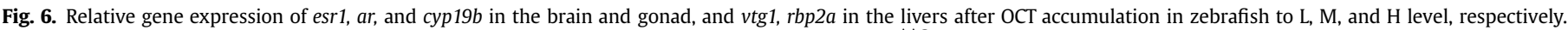

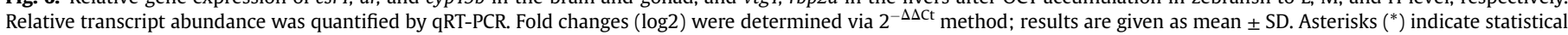
significance $\left({ }^{*} p \leq 0.05,{ }^{* *} p \leq 0.01\right)$.

of intestinal retinoids, the depleted stores of liver retinoids are transported to the eyes and ovaries (Chen et al., 2012). This means that the transcriptional result of $r b p 2 a$ was likely to cause an overall promotion of development based on the increased vitellogenic oocytes in the ovaries and the up-regulation of cyp $19 \mathrm{~b}$ in the brain. Essentially, the expression of $r b p 2 a$ in the liver is likely a negative feedback response to OCT accumulation in zebrafish.

\subsection{Comparison of hormonal activity of OCT accumulation in vivo and in vitro assay}

Multiple hormonal activities of OCT were also observed in an in vitro assay by Kunz and Fent. (2006). Comparison of the hormonal activity of OCT evaluated by in vivo and in vitro assay is shown in Table 2. Both types of assay reveal the antiandrogenicity, androgenicity, and antiestrogenicity of OCT, but the estrogenic activity of OCT was not observed in the in vitro assay. A recent study found that OCT provokes a significant expression of ecdysone receptors in Chironomusriparius embryos, which also indicates the estrogenic activity of OCT in vivo (Ozáez et al., 2016).

Of course, the basic principle of in vitro assay is a simplification of the mechanism in vivo. To a certain extent, in vivo assay can be incarnated by in vitro assay but with simpler operation and high sensitivity. In vitro assay does not allow the researcher to metabolize chemicals as easily, however, so some of the more complex biological effects of chemicals on organisms do not occur. 
Table 2

Comparison of hormonal activities of OCT between in vitro and in vivo assays of zebrafish with H-level OCT accumulation.

\begin{tabular}{|c|c|c|c|c|}
\hline Type of assay & Estrogenic activity & Antiestrogenic activity & Androgenic activity & Antiandrogenic activity \\
\hline $\begin{array}{l}\text { In vitro }{ }^{\mathrm{a}}\left(\mathrm{EC}_{50}\right) \\
\text { In vivo } \text { ("H" level) }^{\mathrm{H}}\end{array}$ & $\begin{array}{l}\times \\
\text { esr1 (+): gonad cyp } 19 b(+) \text { : brain }\end{array}$ & $\begin{array}{l}2.57 \mathrm{E}-3^{\mathrm{b}}\left(\mathrm{mol} \mathrm{L}^{-1}\right) \\
\operatorname{esr} 1(-) \text { : brain }\end{array}$ & $\begin{array}{l}6.27 \mathrm{E}-4^{\mathrm{b}}\left(\mathrm{mol} \mathrm{L}^{-1}\right) \\
\operatorname{ar}(+) \text { : brain }\end{array}$ & $\begin{array}{l}2.45 \mathrm{E}-5^{\mathrm{b}}\left(\mathrm{mol} \mathrm{L}^{-1}\right) \\
\operatorname{ar}(-): \text { gonad }\end{array}$ \\
\hline
\end{tabular}

Metabolization may lead to some loss of the parent compounds, but the production of metabolites with potential activity should also be considered. For example, the UV filter BP-1 as a metabolite of BP-3 shows stronger estrogenic potency than BP-3, which mainly possesses antiestrogenic and antiandrogenic activities (Kunz and Fent, 2006). The metabolites of OCT formed in vivo may have higher hormonal activities than its corresponding parent compound, so it is not surprising that the estrogenic activity of OCT was detected in vivo but not in vitro. Moreover, EDCs affect estrogenic activity through a number of mechanisms including direct interactions (estrogen receptors) or indirect interactions (synthesis of sex steroid hormones, gonad development, and reproduction) (Sun et al., 2014). In some cases, in vivo assay has shown a comparable to better sensitivity to (xeno) estrogens than in vitro assay (Sonavane et al., 2016). It is advisable to apply in vitro assay to detect a specific toxicity, and essentially to create a useful reference for further in vivo assay. Overall, as discussed above, the results of both our in vivo assay and previous in vitro assays provide detailed information for the ecological risk assessment of OCT.

\section{Conclusions}

By the exposure of female and male zebrafish to solutions of elevated OCT concentrations, we found that OCT molecules can indeed transfer rapidly from the solution to zebrafish. As a result, OCT was ultimately accumulated to 2321.01 (L), 31,234.80 (M), and $70,593.38 \mathrm{ng} \mathrm{g}^{-1}(\mathrm{H})$ after $28 \mathrm{~d}$ when the average concentrations of the solutions were controlled at 28.61, 505.62, and $1248.70 \mu \mathrm{g} \mathrm{L}^{-1}$, respectively.

The multiple hormone activities of OCT and their effects on zebrafish were assessed via gross observations, histological observations, and RT-qPCR analysis. Even at the L OCT accumulation level, apparent up-regulation of $r b p 2 a$ was observed in the livers of female and male zebrafish. The higher the OCT accumulation level, the more apparent the adverse effects - for example, female zebrafish with high levels of OCT accumulation showed significant increase in GSI and percentage of vitellogenic oocytes in their ovaries. High OCT accumulation also resulted in multiple hormonal effects in different tissues such as the up-regulation of esr1 in the gonads and the induction of $v \operatorname{tg} 1$ in the liver, indicating that OCT possesses estrogenic activity. The down-regulation of esr1 in the brains of female zebrafish and inhibition of ar in the testes of male zebrafish also demonstrated the antiestrogenicity and antiandrogenicity of OCT. The accumulation of OCT to elevated levels also altered the expression of genes involved in steroidogenesis, i.e., caused the up-regulation in the transcription of cyp19b in the brains of female zebrafish. We also compared in vivo and in vitro assay results regarding antiestrogenic, androgenic, and antiandrogenic activities. We concluded that the hormonal activities revealed by in vivo assay in this study can deepen our understanding of the toxic effects of OCT in the aquatic environment. Overuse of OCT should be avoided, or at least cautiously considered, from the viewpoint of ecological risk control in the future.

\section{Acknowledgements}

This work was supported by the National Natural Science Foundation of China (Grant No. 51508449), National Program of Water Pollution Control in China (Grant No. 2013ZX07310-001). Program for Innovative Research Team in Shaanxi (Grant No. IRT2013KCT-13) and Fund for Postdoctoral Scientific Research Project, China (2015M572531).

\section{References}

Ascenzi, P., Bocedi, A., Marino, M., 2006. Structure-functionrelationship of estrogen receptor alpha and beta: impact on human health. Mol. Asp. Med. 27, 299-402.

Ankley, G.T., Jensen, K.M., Kahl, M.D., Korte, J.J., Makynen, E.A., 2001. Description and evaluation of a short-term reproduction test with the fathead minnow (Pimephales promelas). Environ. Toxicol. Chem. 6, 1276-1290.

Arukwe, A., Nordtug, T., Kortner, T.M., Mortensen, A.S., Brakstad, O.G., 2008. Modulation of steroidogenesis and xenobiotic biotransformation responses in zebrafish (Danio rerio) exposed to water-soluble fraction of crude oil. Environ. Res. 107, 362-370.

Balmer, M.E., Buser, H.R., Müller, M.D., Poiger, T., 2005. Occurrence of some organic UV-filters in wastewater, in surface waters, and in fish from Swiss Lakes. Environ. Sci. Technol. 39, 953-962.

Boscolo Pereira, T.S., Pereira Boscolo, C.N., Felício, A.A., Batlouni, S.R., Schlenk, D. Alves de Almeida, E., 2016. Estrogenic activities of diuron metabolites in female Nile tilapia (Oreochromis niloticus). Chemosphere 146, 497-502.

Blüthgen, N., Zucchi, S., Fent, K., 2012. Effects of the UV-filter benzophenone-3 (oxybenzone) atlow concentrations in zebrafish (Danio rerio). Toxicol. Appl. Pharmacol. 263, 184-194.

Blüthgen, N., Meili, N., Chew, G., Odermatt, A., Fent, K., 2014. Accumulation and effects of the UV-filter Octocrylene in adult and embryonic zebrafish (Danio rerio). Sci. Total. Environ. 476, 207-217.

Bogers, R., De Vries-Buitenweg, S., Van Gils, M., Baltussen, E., Hargreaves, A., van de Waart, B., De Roode, D., Legler, J., Murk, A., 2006. Development of chronic tests for endocrine active chemicals: Part 2: an extended fish early-life stage test with an androgenic chemical in the fathead minnow (Pimephales promelas). Aquat. Toxicol. 80, 119-130.

Buser, H.R., Balmer, M.E., Schmid, P., Kohler, M., 2006. Occurrence of UV-filters 4methylbenzylidene camphor and octocrylene in fish from various Swiss rivers with inputs from wastewater treatment plants. Environ. Sci. Technol. 40, 1427-1431.

Callard, G.V., Tchoudakova, A.V., Kishida, M., Wood, E., 2001. Differential tissue distribution, developmental programming, estrogen regulation and promoter characteristics of cyp19 genes in teleost fish. Tj. Steroid. Biochem. Mol. Biol. 79 305-314.

Chen, L., Hu, C., Huang, C., Wang, Q., Wang, X., Yang, L., et al., 2012. Alterations in retinoid status after long-term exposure to PBDEs in zebrafish (Danio rerio). Aquat. Toxicol. 120-121, 11-18.

Christen, V., Zucchi, S., Fent, K., 2011. Effects of the UV-filter 2-ethyl-hexyl-4 trimethoxycinnamate (EHMC) on expression of genes involved in hormonal pathways in fathead minnows (Pimephales promelas) and link to vitellogenin induction and histology. Aquat. Toxicol. 102, 167-176.

Danovaro, R., Bongiorni, L., Corinaldesi, C., Giovannelli, D., Damiani, E., Astolfi, P. Greci, L., Pusceddu, A., 2008. Sunscreens cause coral bleaching by promoting viral infections. Environ. Health. Persp. 116, 441-447.

Díaz-Cruz, M.S., Gago-Ferrero, P., Llorca, M., Barceló, D., 2012. Analysis of UV-filters in tap water and other clean waters in Spain. Anal. Bioanal. Chem. 402, 2325-2333.

Engler-Chiurazzi, E.B., Brown, C.M., Povroznik, J.M., Simpkins, J.W., 2016. Estrogens as neuroprotectants:Estrogenic actions in the context of cognitive aging and brain injury. Prog. Neurobiol. (in press).

Fent, K., Zenker, A., Rapp, M., 2010. Widespread occurrence of estrogenic UV-filters in aquatic ecosystems in Switzerland. Environ. Pollut. 158, 1817-1824.

Filby, A.L., Thorpe, K.L., Maack, G., Tyler, C.R., 2007. Gene expression profiles revealing the mechanisms of anti-androgen- and estrogen-induced feminization in fish. Aquat. Toxicol. 81, 219-231.

Gago-Ferrero, P., Alonso, M.B., Bertozzi, C.P., Marigo, J., Barbosa, L.r., Cremer, M. Secchi, E.R., Azevedo, A., Lailson-Brito Jr., J., Torres, J.P., 2013. First determination of UV filters in marine mammals. Octocrylene levels in Franciscana dolphins. 
Environ. Sci. Technol. 47, 5619-5625

Gago-Ferrero, P., Diaz-Cruz, M.S., Barcelo, D., 2015. UV filters bioaccumulation in fish from Iberian river basin. Sci. Total. Environ. 518-519, 518-525.

Gomez, E., Bachelot, M., Boillot, C., Munaron, D., Chiron, S., de Casellas, C., Fenet, H., 2012. Bioconcentration of two pharmaceuticals (benzodiazepines) and two personal care products (UV filters) in marine mussels (Mytilus galloprovincialis) under controlled laboratory conditions. Environ. Sci. Pollut. R. 7, 2561-2569.

Hoffmann, J., Torontali, S., Thomason, R., Lee, D., Brill, J., Price, B., Carr, G., Versteeg, D., 2006. Hepatic gene expression profiling using Genechips in zebrafish exposed to $17 \alpha$-ethynylestradiol. Aquat. Toxicol. 79, 233-246.

Hossain, M.S., Larsson, A., Scherbak, N., Olsson, P.E., Orban, L., 2008. Zebrafish androgen receptor: isolation, molecular, and biochemical characterization. Biol. Reprod. 78, 361-369.

Hinfray, N., Palluel, O., Turies, C., Cousin, C., Porcher, J.M., Brion, F., 2006. Brain and gonadal aromatase as potential targets of endocrine disrupting chemicals in a model species, the zebrafish (Danio rerio). Environ. Toxicol. 4, 332-337.

Inui, M., Adachi, T., Takenaka, S., Inui, H., Nakazawa, M., Ueda, M., Watanabe, H., Mori, C., Iguchi, T., Miyatake, K., 2003. Effect of UV screens and preservativeson vitellogenin and choriogenin production in male medaka (Oryzias latipes). Toxicology 194, 43-50.

Kazeto, Y., Ijiri, S., Place, A.R., Zohar, Y., Trant, J.M., 2001. The 5'-Flanking regions of CYP19A1 and CYP19A2 in zebrafish. Biochem. Biophys. Res. Commun. 288 503-508.

Kim, S., Jung, D., Kho, Y., Choi, K., 2014. Effects of benzophenone-3 exposure on endocrine disruption and reproduction of Japanese medaka (Oryzias latipes)A two generation exposure study. Aquat. Toxicol. 155, 244-252.

Kuhl, A.J., Manning, S., Brouwer, M., 2005. Brain aromatase in Japanese medak (Oryzias latipes): molecular characterization and role in xenoestrogen-induced sex reversal. J. Steroid. Biochem. Mol. Biol. 96, 67-77.

Kunz, P.Y., Fent, K., 2006. Multiple hormonal activities of UV filters and comparison of in vivo and in vitro estrogenic activity of ethyl-4-aminobenzoate in fish. Aquat. Toxicol. 79, 305-324.

Kupper, T., Plagellat, C., Brändli, R.C., de Alencastro, L.F., Grandjean, D., Tarradellas, J., 2006. Fate and removal of polycyclic musks, UV filters and biocides during waste water treatment. Water. Res. 40, 2603-2612.

Langford, K.H., Reid, M.J., Fjeld, E., Oxnevad, S., Thomas, K.V., 2015. Environmental occurrence and risk of organic UV filters and stabilizers in multiple matrices in Norway. Environ. Int. 80, 1-7.

Levy, G., Lutz, I., Kruger, A., von Tumpling, W., Kloas, W., 2004. Retinol-binding protein as a biomarker to assess endocrine-disrupting compounds in the environment. Anal. Bioanal. Chem. 378, 676-683.

Liu, H., Liu, L., Xiong, Y., Yang, X., Luan, T., 2010. Simultaneous determination of UV filters and polycyclic musks in aqueous samples by solid-phase microextraction and gas chromatography-mass spectrometry. J. Chromatogra. A 1217 6747-6753.

Livak, K.J., Schmittgen, T.D., 2001. Analysis of relative gene expression data using real-time quantitative PCR and the 2(-Delta Delta C(T)). Methods 25, 402-408.

Loraine, G.A., Pettigrove, M.E., 2006. Seasonal variations in concentrations of pharmaceuticals and personal care products in drinking water and reclaimed wastewater in Southern California. Environ. Sci. Technol. 40, 687-695.

Lubzens, E., Young, G., Bobe, J., Cerda, J., 2010. Oogenesis in teleosts: how fish eggsare formed. Gen. Comp. Endocrinol. 165, 367-389.

Martyniuk, C.J., Gerrie, E.R., Popesku, J.T., Ekker, M., Trudeau, V.L., 2007. Microarray analysis in the zebrafish (Danio rerio) liver and telencephalon after exposure to low concentration of 17alpha-ethinylestradiol. Aquat. Toxicol. 84, 38-49.

McAllister, B.G., Kime, D.E., 2003. Early life exposure to environmental levels of the aromatase inhibitor tributyltin causes masculinisation and irreversible sperm damage in zebrafish (Danio rerio). Aquat. Toxicol. 3, 309-316.

McKearin, D.M., Barton, M.C., Keller, M.J., Shapiro, D.J., 1986. Estrogen induces transcriptionofthe Xenopus zaeuis serum RetinolbindingProtein gene. J. Biol Chem. 11, 4939-4942.

Mouriec, K., Gueguen, M.M., Manuel, C., Percevault, F., Thieulant, M.L., Pakdel, F. Kah, O., 2009. Androgens upregulate cyp19a1b (aromatase B) gene expression in the brain of zebrafish (Danio rerio) through estrogen receptors. Biol. Reprod.
80, 889-896.

Nagahama, Y., Yamashita, M., 2008. Regulation of oocyte maturation in fish. Dev.Growth. Differ 50, 195-221.

OECD Guideline 305, 1996. Bioconcentration: Flow-through FishTest.

Ozáez, I., Morcillo, G., Martínez-Guitarte, J.L., 2016. Ultraviolet filters differentially impact the expression of key endocrine and stress genes in embryos and larvae of Chironomus riparius. Sci. Total. Environ. 557-558, 240-247.

Pereira, T.S.B., Moreira, R.G., Batlouni, S.R., Moreira, R.G., Batlouni, S.R., 2013. Dynamics of ovarian maturation during the reproductive cycle of Metynnis maculatus, a reservoir invasive fish species (Teleostei: characiformes). Neotrop. Ichthyol. 11, 821-830.

Poiger, T., Buser, H.R., Balmer, M.E., Bergqvist, P.A., Müller, M.D., 2004. Occurence of UV filter compounds from sunscreens in surface waters: regional mass balance in two Swiss lakes. Chemosphere 55, 951-963.

Reimers, M.J., Flockton, A.R., Tanguay, R.L., 2004. Ethanol-and acetaldehyde -mediated developmental toxicity in zebrafish. Neurotoxicol. Teratol. 26, $769-781$.

Rodil, R., Quintana, P., Lopez-Mahia, S., Muniategui-Lorenzo, D., Prada-Rodriquez, 2008. Multiclass determination of sunscreen chemicals in water samples by liquid chromatography-tandem mass spectrometry. Anal. Chem. 80, 1307-1315.

Rodil, R., Moeder, M., Altenburger, R., Schmitt-Jansen, M., 2009. Photostability and phytotoxicity of selected sunscreen agents and their degradation mixtures in water. Anal. Bioanal. Chem. 395, 1513-1524.

Schlumpf, M., Kypke, K., Vökt, C.C., Birchler, M., Durrer, S., Faass, O., Ehnes, C., Fuetsch, M., Gaille, C., Henseler, M., Hofkamp, L., Maerkel, K., Reolon, S., Zenker, A., Timms, B., Tresguerres, J.A.F., Lichtensteiger, W., 2008. Endocrine active UV-filters: developmental toxicity and exposure through breast milk. Chimia 62, 345-351.

Scholz, S., Gutzeit, H.O., 2000. 17- $\alpha$-ethinylestradiol affects reproduction, sexual differentiation and aromatase gene expression of the medaka (Oryzias latipes). Aquat. Toxicol. 50, 363-373.

Simpson, E.R., Mahendroo, M.S., Means, G.D., Kilgore, M.W., Hinshelwood, M.M., Graham-Lorence, S., Amarneh, B. Ito, Y, Fisher CR, Michael, M.D. 1994. Aromatase cytochrome P450, the enzyme responsible for estrogen biosynthesis. Endocr. Rev. 15, 342-355.

Sonavane, M., Creusot, N., Maillot-Maréchal, E., Péry, A., Brion, F. Aït-Aïssa, S., 2016 Zebrafish-based reporter gene assays reveal different estrogenic activities in river waters compared to a conventional human-derived assay. Sci. Total. Environ. 550, 934-939.

Sumpter, J.P., Jobling, S., 1995. Vitellogensis as a biomaker for estrogenic comtanmnation of aquatic environment. Environ. Health. Persp 103, 173-178.

Sun, L., Jin, R., Peng, Z., Zhou, Q., Qian, H., Fu, Z., 2014. Effects of trilostane and fipronil on the reproductive axis in an early life stage of the Japanese medaka (Oryzias latipes). Ecotoxicology 23, 1044-1054.

Tsui, M.M.P., Leung, H.W., Kwan, B.K.Y., Ng, K.Y., Yamashita, N., Taniyasu, S., Lam, P.K.S., Murphy, M.B., 2015. Occurrence, distribution and ecological risk assessment of multiple classes of UV filters in marine sediments in Hong Kong and Japan. J. Hazard. Mater. 292, 180-187.

Weisbrod, C.J., Kunz, P.Y., Zenker, A.K., Fent, K., 2007. Effects of the UV filter benzophenone-2 on reproduction in fish. Toxicol. App. Pharmacol. 225, 255-266.

Wintz, H., Yoo, L.J., Loguinov, A., Wu, Y.Y., Steevens, J.A., Holland, R.D., Beger, R.D., Perkins, E.J., Hughes, O., Vulpe, C.D., 2006. Gene expression profiles in fathead minnow exposed to 2,4-DNT: correlation with toxicity in mammals. Toxicol. Sci. $94,71-82$.

Zucchi, S., Blüthgen, N., Ieronimo, A., Fent, K., 2010. The UV-absorber benzophenone-4 alters transcripts of genes involved in hormonal pathways in zebrafish (Danio rerio) eleuthero-embryos and adult males. Toxicol. App. Pharmacol. 250, 137-146.

Zucchi, S., Oggier, D.M., Fent, K., 2011. Global gene expression profile induced by the UV-filter 2-ethyl-hexyl-4-trimethoxycinnamate (EHMC) in zebrafish (Danio rerio). Environ. Pollut. 159, 3086-3096. 